\title{
Cancer in ulcerative colitis
}

Since the first reports of carcinoma of the large intestine occurring in patients with ulcerative colitis (Crohn and Rosenberg, 1925; Yeomans, 1927; Bargen, 1928) there have been many attempts to estimate the risk of malignant change. There have been difficulties in defining the population of patients at risk because different hospitals study samples which are influenced by variations in methods of selection (Welch and Hedberg, 1965). For example, the incidence of carcinoma in ulcerative colitis in medically-managed patients is lower than in those treated surgically. Despite these difficulties there would seem to be general agreement that the incidence lies between 3 and $5 \%$ of all cases (Edwards and Truelove, 1964). When comparing this figure with the incidence of cancer of the colon and rectum in the general population the risk of malignant change in patients with ulcerative colitis is between five and ten times greater than persons without the disease (Goldgraber and Kirsner, 1964), which is small in terms of the absolute number of cases affected.

The next step has been to show how this increased risk varies with length of history and the clinical type of colitis. Here again there is general agreement that the risk of malignant change begins when the patient has had symptoms for approximately 10 years and particularly in those in whom the disease starts early in life.

Recent observations by Professor Goligher and his colleagues (de Dombal, Watts, Watkinson, and Goligher, 1966) and Hinton (1966) have confirmed that patients with total colitis are most at risk from malignant change and that distal forms of the disease have an almost insignificant chance of developing carcinoma. Age is also important in the study of cancer and ulcerative colitis, for MacDougall (1964a) has clearly shown that the incidence of cancer in colitis beginning before the age of 25 years is twice as great as those with symptoms beginning after this age.

Professor Goligher, in an attempt to measure the risk of cancer in patients with total colitis, has used the concept of the patient year introduced by Dennis and Karlson (1961) and MacDougall (1964b). These studies indicate that the risk is extremely low in the first 10 years but rises gradually until after 25 years the annual risk is nearly $6 \%$. They emphasize that this risk occurs every year, and measure the cumulative risk after 10 years and over a period of 25 years in the individual patient as no less than $42 \%$. From these figures they argue the case for prophylactic colectomy for patients with a long history of total colitis.

The prognosis of cancer in ulcerative colitis is generally regarded as poor (Slaney and Brooke, 1959). It certainly seems much worse than the results of treatment in cancer of the colon and rectum without colitis (Bussey, 1963). However, Hinton reports from St. Mark's Hospital an overall fiveyear survival rate of $40 \%$ and points out that in half the cases in which the tumours were of low or average-grade malignancy the five-year survival is $75 \%$. These are figures from a specialist hospital and cannot be regarded as representative of the country as a whole. In any case the death rate is great enough to lend support to those who are seeking to prevent the development of cancer by prophylactic colectomy in selected patients.

The malignant tumours arising in ulcerative colitis are often multiple and scattered more evenly throughout the large bowel in contrast to the high incidence of rectal as compared with colon cancer in the general population (Edling and Eklöf, 1961). The growths are commonly flat and infiltrating. Histologically there is a high incidence of poorly differentiated and mucus-secreting tumours. This is one of the main factors contributing to the poor prognosis. Inspection of the mucosal surface of large bowel affected by colitis and cancer shows some significant appearances. It is common to see areas of polypoid overgrowth of the mucous membrane which takes the form of a low villous growth pattern or obvious papillary tumours (Dawson and Pryse-Davies, 1959). These polypoid changes represent a pre-cancerous stage but they must be clearly differentiated from the much more common inflammatory or pseudo-polyps. Transformation of inflammatory polyps into carcinoma is probably 
a rare event. Pre-cancerous changes are often diffuse which means that total excision of the large intestine is necessary for patients with colitis and cancer. If prophylactic colectomy is advisable for some long-standing colitics then any operation other than total proctocolectomy will leave behind a potentially malignant rectum. There are a number of reports in the literature of carcinoma arising in the rectum after ileo-rectal anastomosis (Hudson, 1961; Steedman, 1963).

In contrast to the amount of research into the statistical aspects of the association of ulcerative colitis and cancer of the large bowel there have been too few studies into the histopathology of the pre-cancerous phase of ulcerative colitis, and its relationship to extent of disease and length of history. It is possible that there are more subtle changes of a morphological character than the ones mentioned above which are an indication that the epithelial instability of ulcerative colitis ceases to be a regenerative hyperplasia for purposes of repair and becomes a neoplastic hyperplasia. Further studies along these lines are needed.

Having defined the type of patient with ulcerative colitis most susceptible to malignant change the treatment of the individual remains a formidable problem. Prophylactic proctocolectomy as advised by Professor Goligher and his colleagues (1966) may be justified but such a policy would certainly result in a number of colectomies being performed for patients who were not going to develop carcinoma. Moreover, there is difficulty in persuading a patient who has spent many of the best years of his life getting adjusted to his colitis that a major operation with a permanent ileostomy is necessary. Such an operation carries a mortality and morbidity which must be taken into account. Moreover, some patients developing carcinoma in colitis have few symptoms and are in remarkably good general health. On the other hand, as pointed out by the Leeds workers, there is sufficient risk to health and life other than cancer in some long-standing colitics on medical treatment alone to make a proctocolectomy attractive as a final answer to the whole problem.

Despite great progress in research, we have still not defined the colitic patient most at risk from malignant change in sufficiently precise terms applicable to the individual sufferer. Further tests are needed which will tell us that the individual patient is in a pre-cancerous phase. This is the time for prophylactic surgery. Exfoliative cytology is showing the way towards the prevention of carcinoma of the cervix by the detection of this phase of 'in situ' carcinoma. Up to the present time exfoliative cytology of the colon has proved disappointing, but further effort in this field might be rewarding.

B. C. MORSON

\section{REFERENCES}

Bargen, J. A. (1928). Chronic ulcerative colitis associated with malignant disease. Arch. Surg., 17, 561-576.

Bussey, H. J. R. (1963). The long-term results of surgical treatment of cancer of the rectum. Proc. roy. Soc. Med., 56, $494-496$.

Crohn, B. B., and Rosenberg, H. (1925). The sigmoidoscopic picture of ulcerative colitis (non-specific). Amer J. med. Sci., 170, $220-228$.

Dawson, I. M. P., and Pryse-Davies, J. (1959). The development of carcinoma of the large intestine in ulcerative colitis. Brit.J. Surg., 47, 113-128.

Dennis, C., and Karlson, K. E. (1961). Cancer risk in ulcerative colitis: Formidability per patient-year of late disease. Surgery, 50, 568-571.

de Dombal, F. T., Watts, J. Mck., Watkinson, G., Goligher J. C. (1966). Local Complications of ulcerative colitis; Structure, pseudo-polyposis and carcinoma of the colon and rectum Brit. Med. J. 1, 1442-1447.

Edling, N. P. G., and Eklöf, O. (1961). Distribution of malignancy in ulcerative colitis. Gastroenterology, 41, 465-466.

Edwards, F. C., and Truelove, S. C. (1964). Course and prognosis of ulcerative colitis. Part IV. Carcinoma of the colon. Gut, 5, $15-22$.

Goldgraber, M. B., and Kirsner, J. B. (1964). Carcinoma of the colon in ulcerative colitis. Cancer (Baltimore), 17, 657-665.

Hinton, J. M. (1966). Carcinoma in ulcerative colitis. Gut. 7, 427.

Hudson, C. N. (1961). Carcinoma of the rectum following ileoproctostomy and colectomy for ulcerative colitis Proc. roy. Soc. Med., 54, 514-516.

MacDougall, I. P. M. (1964a). Clinical identification of those cases of ulcerative colitis most likely to develop cancer of the bowel. Dis. Colon Rect., 7, 447-450.

- (1964b). The cancer risk in ulcerative colitis, Lancet, 2, 655-658.

Slaney, G., and Brooke, B. N. (1959). Cancer in ulcerative colitis, Ibid., 2, 694-698.

Steedman, P. K. (1963). Carcinoma in an ano-rectal stump years after a total colectomy for ulcerative colitis. Med. J. Aust., 2, 407-408.

Welch, C. E., and Hedberg, S. E. (1965). Colonic cancer in ulcerative colitis and idiopathic colonic cancer. J. Amer. med. Ass., $191,815-818$.

Yeomans, F. C. (1927). Carcinomatous degeneration of rectal adenomas: Report of 7 cases. J. Amer. med. Ass., 89, 852-854. 